\title{
Lupeol and its esters: NMR, powder XRD data and in vitro evaluation of cancer cell growth
}

\author{
Aline Teixeira Maciel e Silva ${ }^{1}$, Cássia Gonçalves Magalhães*2, Lucienir Pains Duarte ${ }^{3}$, Wagner da \\ Nova Mussel $^{3}$, Ana Lucia Tasca Gois Ruiz ${ }^{4}$, Larissa Shiozawa ${ }^{4}$, João Ernesto de Carvalho ${ }^{4,5}$, Izabel \\ Cristina Trindade6, Sidney Augusto Vieira Filho ${ }^{6}$
}

\begin{abstract}
${ }^{1}$ Departamento de Produtos Farmacêuticos, Faculdade de Farmácia, Universidade Federal de Minas Gerais, Belo Horizonte, Minas Gerais, Brasil, ${ }^{2}$ Departamento de Química, Centro de Ciências Exatas e Naturais, Universidade Estadual de Ponta Grossa, Ponta Grossa, Paraná, Brasil, ${ }^{3}$ Departamento de Química, Instituto de Ciências Exatas, Universidade Federal de Minas Gerais, Belo Horizonte, Minas Gerais, Brasil, ${ }^{4}$ Centro Pluridisciplinar de Pesquisas Químicas, Biológicas e Agrícolas,

Universidade Estadual de Campinas, Paulínia, São Paulo, Brasil, ${ }^{5}$ Faculdade de Ciências Farmacêuticas, Universidade Estadual de Campinas, Campinas, São Paulo, Brasil, ${ }^{6}$ Departamento de Farmácia, Escola de Farmácia, Universidade Federal de Ouro Preto, Ouro Preto, Minas Gerais, Brazil
\end{abstract}

\begin{abstract}
The triterpene lupeol (1) and some of its esters are secondary metabolites produced by species of Celastraceae family, which have being associated with cytotoxic activity. We report herein the isolation of $\mathbf{1}$, the semi-synthesis of eight lupeol esters and the evaluation of their in vitro activity against nine strains of cancer cells. The reaction of carboxylic acids with 1 and DIC/DMAP was used to obtain lupeol stearate (2), lupeol palmitate (3) lupeol miristate (4), and the new esters lupeol laurate (5), lupeol caprate (6), lupeol caprilate (7), lupeol caproate (8) and lupeol 3',4'-dimethoxybenzoate (9), with high yields. Compounds 1-9 were identified using FT-IR, ${ }^{1} \mathrm{H},{ }^{13} \mathrm{C}-\mathrm{NMR}, \mathrm{CHN}$ analysis and XRD data and were tested in vitro for proliferation of human cancer cell activity. In these assays, lupeol was inactive $\left(\mathrm{GI}_{50}>250 \mu \mathrm{g} /\right.$ $\mathrm{mL}$ ) while lupeol esters 2 -4 and 7 - 9 showed a cytostatic effect. The XRD method was a suitable tool to determine the structure of lupeol and its esters in solid state. Compound $\mathbf{3}$ showed a selective growth inhibition effect on erythromyeloblastoid leukemia (K-562) cells in a concentration-dependent way. Lupeol esters 4 and $\mathbf{9}$ showed a selective cytostatic effect with low $\mathrm{GI}_{50}$ values representing promising prototypes for the development of new anticancer drugs.
\end{abstract}

Keywords: Lupeol/in vitro evaluation. Lupeol ester. K-562 cells. XRD method. Antiproliferative effect.

\section{INTRODUCTION}

Despite the efforts to develop new strategies of cancer prevention and therapy (Galmarini, Galmarini, Galmarini, 2012), cancers still represent a worldwide problem of public health. According to the Word Health Organization (Ferlay et al., 2012), around 14 million of the new cancer cases occurred in 2012 (57\% of this total in less developed regions). Among the strategies to treat cancer, cancer chemotherapeutic agents represent crucial tools basically aiming to eliminate or at least inhibit

\footnotetext{
*Correspondence: C. G. Magalhães. Departamento de Química, Centro de Ciências Exatas e Naturais, Universidade Estadual de Ponta Grossa, 84.030900, Ponta Grossa, Paraná, Brasil. Phone: +55 - 42 - 3220-3062. E-mail: cassiagmag@yahoo.com.br
}

tumor cell growth (Galmarini, Galmarini, Galmarini, 2012; Chabner, Roberts, 2005). Considering all antitumor chemotherapeutic arsenal approved between 1940 s and 2014, 49\% (85 chemical entities) were natural products per si or directly derived from them (Newman, Cragg, 2016).

Among natural products, triterpenoids have been considered a promising class for cancer chemoprevention and chemotherapy (Salminen et al., 2008; Lachance et al., 2012; Gali-Muhtasib et al., 2015), and they have been highlighted as antineoplastic agents (DallaVechia, Gnoatto, Gosmann, 2009; Laszczyk, 2009; Siddique, Saleem, 2011; Sultana, 2011).

Triterpenes inhibit tumor growth, cellular cycle progression, and induce the apoptosis of tumor cells both in vitro and in vivo tests besides presenting anti- 
inflammatory, antioxidant and antiangiogenic effects (Laszczyk, 2009; Siddique, Saleem, 2011). Lupeol (1, Figure 1), a pentacyclic triterpene, occurs in many medicinal plants (Laszczyk, 2009), such as in leaves of Maytenus salicifolia Reissek (Celastraceae) (Núñez et al., 2005). This compound has displayed anti-inflammatory property (Salminen et al., 2008; Saleem, 2009; Shahlaei et al., 2013), protective effect during low-density lipoprotein (LDL) oxidation (Geetha, Varalakshmiu, Latha, 1998; Andrikopoulos et al., 2003), and anticancer activity against different cell lines [melanoma (G361, 451Lu and WM35), T-lymphoblastic leukemia (CEM), breast carcinoma (MCF-7 and MDA-MB-231), lung carcinoma (A-549), multiple myeloma (RPMI 8226) and cervical carcinoma (HeLa)] (Saleem, 2009; Saleem et al.; 2008; Gallo, Sarachine, 2009).

Some natural lupeol esters also present promising biological effects such as antimalarial (Fotie et al., 2006) and acetylcholinesterase inhibitory activities (Gurovic et al., 2010). Based on these promising activities, some lupeol esters have been synthetized and evaluated for different activities (Li et al., 2013; Lachance et al., 2012; Reddy et al., 2009; Sudhahar, Kumar, Varalaksmi, 2006a). For example, lupeol linoleate has been described as effective to reduce hypercholesterolemia (Sudhahar, Kumar, Varalaksmi, 2006a; Sudhahar, Kumar, Varalaksmi, 2006b; Sudhahar et al., 2007a) and also as a protective agent in different oxidative stress conditions (Sudhahar, Kumar, Varalaksmi, 2006a; Sunitha, Nagaraj, Varalaksmi, 2001; Sudhahar et al., 2007b; Sudhahar et al., 2008; Sudhahar, Veena, Varalaksmi, 2008).

The aim of this work was the semi-synthesis of eight lupeol esters, from which five (5 to 9) are new ones. The compounds were characterized by Fourier transform infrared (FT-IR), nuclear magnetic resonance $\left({ }^{1} \mathrm{H}\right.$ and $\left.{ }^{13} \mathrm{C} \mathrm{NMR}\right)$ spectroscopy, $\mathrm{CHN}$ analysis and powder X-ray diffractometry (XRD). Moreover, lupeol and the eight lupeol esters were evaluated regarding their antiproliferative in vitro potential against a human cell lines panel.

\section{RESULTS AND DISCUSSION}

\section{Synthesis and identification of lupeol esters}

Lupeol (1) was isolated from hexane branch extract of $M$. salicifolia through phytochemical processes as described in the literature (Magalhães et al., 2011). The esters $\mathbf{2}$ to 9 were obtained reacting $\mathbf{1}$ with an adequate carboxylic acid and the DIC/DMAP reagents (Figure 1), with yields ranging from 86 to $96 \%$. The ${ }^{1} \mathrm{H}$ and ${ }^{13} \mathrm{C}$ NMR chemical shift assignments of compound 1 (S3) were in accordance with the spectral data published by Shahlaei and coworkers (2013).

The structures of lupeol esters ( 2 to 9 ) were confirmed due to the disappearance of signal at $\delta_{\mathrm{C}} 71.0$, in the ${ }^{13} \mathrm{C}$ NMR spectra ( $\mathbf{S} 4$ to $\mathbf{S 1 1}$ ), corresponding to carbon 3 bonds in the hydroxyl group, the presence of signal at $\delta_{\mathrm{C}} 80.0$ associated to $\mathrm{C}-\mathrm{O}-\mathrm{C}$, together the of the signal at $\sim \delta_{\mathrm{C}} 171.0(\mathrm{C}=\mathrm{O})$. The signal associated to $\mathrm{C}=\mathrm{O}$ group to compound 9 appeared at $\delta_{\mathrm{C}} 166.10$ due to the influence of 3',4'-dimethoxybenzoate group (Mahato, Kundu, 1994). The physical chemical data (IR, ${ }^{1} \mathrm{H}$ and ${ }^{13} \mathrm{C}$ NMR and $\mathrm{CHN}$ analysis) of compounds $\mathbf{1}$ to $\mathbf{9}$ are described below, as well as the amount obtained ( $\mathrm{mmol})$ and percent yield for the esters 2 to 9.

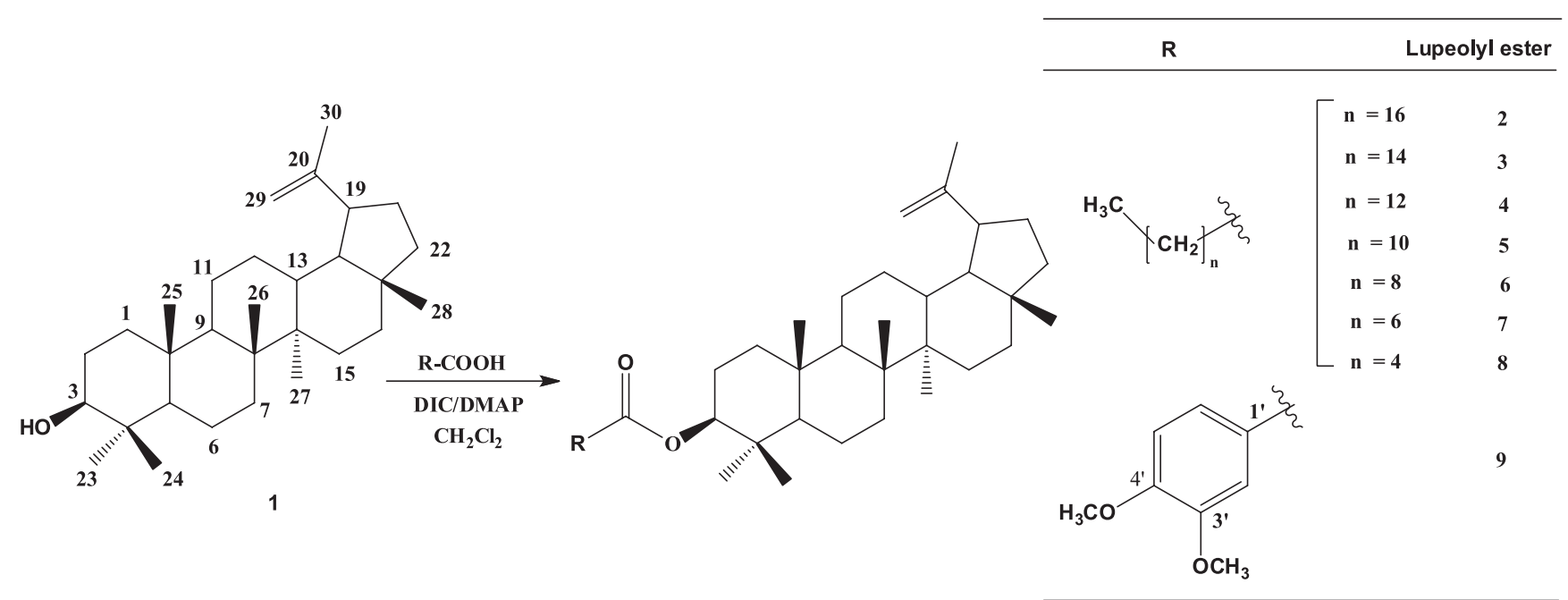

FIGURE 1 - Scheme of lupeol (1) esterification using DIC/DMAP reagents, to obtain lupeol esters 2 to 9. 
33-Lup-20(29)-en-3-ol (lupeol) (1): $426 \mathrm{~g} \mathrm{~mol}^{-1}$ [mp 213.8 $\left.-215.2^{\circ} \mathrm{C}\right]$.

IR $\left(\mathrm{KBr}, \mathrm{cm}^{-1}\right): 3550,3400,3295,2920,2850,1640$ (weak) 1470, 1455, 1440, 1380, 1360, 1140, 1110, 1040, 985, 880.

${ }^{1} \mathrm{H}$ NMR $\left(\mathrm{CDCl}_{3}, 200 \mathrm{MHz}\right) \delta: 4.57$ (s, H-29a), 4.68(s, H-29b), 3.21(dd, $J=2.0 ; 6.0$ Hz, H-3) , 1.68, 1.00, 0.97, $0.95,0.83,0.79,0.76\left(21 \mathrm{H}, 7 \mathrm{~s}, 7 \mathrm{CH}_{3}\right)$.

${ }^{13} \mathrm{C}$ NMR $\left(\mathrm{CDCl}_{3}, 50 \mathrm{MHz}\right) \delta: 38.08(\mathrm{C}-1), 27.43(\mathrm{C}-2)$, 79.05 (C-3), 38.73 (C-4), 55.33 (C-5), 18.34 (C-6), 34.31 (C-7), 40.86 (C-8), 50.47 (C-9), 37.20 (C-10), 20.95 (C-11), 25.17 (C-12), 38.88 (C-13), 42.86 (C-14), 27.47 (C-15), 35.61 (C-16), 43.02 (C-17), 48.34 (C-18), 48.00 (C-19), 150.98 (C-20), 29.87 (C-21), 40.02 (C-22), 28.00 (C-23), 15.37 (C-24), 16.13 (C-25), 16.00 (C-26), 14.57 (C-27), 18.02 (C-28), 109.33 (C-29), 19.32 (C-30).

$\mathrm{CHN}$ analysis: Calcd for $\mathrm{C}_{30} \mathrm{H}_{50} \mathrm{O}: \mathrm{C}, 84.44 ; \mathrm{H}, 11.81 \%$. Found: C, 84.49; H, 11.03\%.

Lupeol stearate (2): $692 \mathrm{~g} \mathrm{~mol}^{-1}$, [0.85 mmol (86\% yield)], (mp $\left.51.7-52.7^{\circ} \mathrm{C}\right)$.

IR $\left(\mathrm{KBr}, \mathrm{cm}^{-1}\right): 3071,2915,2850(\mathrm{CH}), 1727(\mathrm{C}=\mathrm{O}), 1640$, 1172 (CO-O-C), 882.

${ }^{1} \mathrm{H}$ NMR $\left(\mathrm{CDCl}_{3}, 200 \mathrm{MHz}\right) \delta: 4.68(\mathrm{~s}, \mathrm{H}-29 \mathrm{~b}), 4.58$ (s, H-29a), 4.49 ( dd, $J=4.0 ; 8.0$ Hz, H-3), 1.68, 1.06, 0.94, $0.90,0.88,0.83,0.79\left(21 \mathrm{H}, 7 \mathrm{~s}, 7 \mathrm{CH}_{3}\right)$.

${ }^{13} \mathrm{C}$ NMR $\left(\mathrm{CDCl}_{3}, 50 \mathrm{MHz}\right) \delta: 38.40\left(\mathrm{CH}_{2}, \mathrm{C}-1\right), 23.74$ $\left(\mathrm{CH}_{2}, \mathrm{C}-2\right), 80.61$ (C,C-3), 37.83 (C,C-4), 55.37 (CH,C-5), $18.20\left(\mathrm{CH}_{2}, \mathrm{C}-6\right), 34.20\left(\mathrm{CH}_{2}, \mathrm{C}-7\right), 40.84(\mathrm{C}, \mathrm{C}-8), 50.33$ (CH, C-9), 37.08 (C, C-10), $20.94\left(\mathrm{CH}_{2}, \mathrm{C}-11\right), 25.10$ $\left(\mathrm{CH}_{2}, \mathrm{C}-12\right), 38.04(\mathrm{CH}, \mathrm{C}-13), 42.9(\mathrm{C}, \mathrm{C}-14), 27.43$ $\left(\mathrm{CH}_{2}, \mathrm{C}-15\right), 35.57\left(\mathrm{CH}_{2}, \mathrm{C}-16\right), 42.82(\mathrm{C}, \mathrm{C}-17), 48.28$ (C, C-18), 48.00 (C,C-19), 150.94 (C, C-20), $29.70\left(\mathrm{CH}_{2}\right.$, $\mathrm{C}-21), 40.00\left(\mathrm{CH}_{2}, \mathrm{C}-22\right), 27.97\left(\mathrm{CH}_{3}, \mathrm{C}-23\right), 16.57\left(\mathrm{CH}_{3}\right.$, $\mathrm{C}-24), 16.17\left(\mathrm{CH}_{3}, \mathrm{C}-25\right), 15.97\left(\mathrm{CH}_{3}, \mathrm{C}-26\right), 14.51\left(\mathrm{CH}_{3}\right.$, $\mathrm{C}-27), 18.00\left(\mathrm{CH}_{3}, \mathrm{C}-28\right), 109.36\left(\mathrm{CH}_{2}, \mathrm{C}-29\right), 19.28$ $\left(\mathrm{CH}_{3}, \mathrm{C}-30\right), 173.72\left(\mathrm{C}, \mathrm{C}-1\right.$ ') $, 34.86\left(\mathrm{CH}_{2}, \mathrm{C}-2\right.$ ') $), 25.17$ $\left(\mathrm{CH}_{2}, \mathrm{C}-3\right.$ ') $), 29.26\left(\mathrm{CH}_{2}, \mathrm{C}-4\right.$ ') $29.27\left(\mathrm{CH}_{2}, \mathrm{C}-5\right.$ ') $), 29.38$ $\left(\mathrm{CH}_{2}, \mathrm{C}-6\right.$ ') $29.59\left(\mathrm{CH}_{2}, \mathrm{C}^{\prime} 7^{\prime}\right), 14.13\left(\mathrm{CH}_{2}, \mathrm{C}-8^{\prime}\right), 29.82$ $\left(\mathrm{CH}_{2}, \mathrm{C}-9\right.$ ') $, 29.70\left(\mathrm{CH}_{2}, \mathrm{C}-10^{\prime}\right), 29.70\left(\mathrm{CH}_{2}, \mathrm{C}-11^{\prime}\right)$, $29.70\left(\mathrm{CH}_{2}, \mathrm{C}-12^{\prime}\right), 29.70\left(\mathrm{CH}_{2}, \mathrm{C}-13^{\prime}\right), 29.59\left(\mathrm{CH}_{2}\right.$, C-14'), $29.47\left(\mathrm{CH}_{2}, \mathrm{C}-15^{\prime}\right), 31.94\left(\mathrm{CH}_{2}, \mathrm{C}-16^{\prime}\right), 22.70$ $\left(\mathrm{CH}_{2}, \mathrm{C}-17^{\prime}\right), 14.13\left(\mathrm{CH}_{3}, \mathrm{C}-18^{\prime}\right)$.

CHN analysis: Calcd for $\mathrm{C}_{48} \mathrm{H}_{84} \mathrm{O}_{2}$ : C, 83.17; H, 12.21\%. Found: C, 82.97; H, 13.41\%.

Lupeol palmitate (3): 664 g.mol ${ }^{-1}$, [0.90 mmol (90\% yield)], (mp $\left.52.0-56.0^{\circ} \mathrm{C}\right)$.

IR $\left(\mathrm{KBr}, \mathrm{cm}^{-1}\right): 3071,2915,2850(\mathrm{CH}), 1726(\mathrm{C}=\mathrm{O}), 1641$, 1171 (CO-O-C), 881.

${ }^{1} \mathrm{H}$ NMR (CDCl, $\left.200 \mathrm{MHz}\right)$ 8:4.57 (s, H-29a), 4.68(s,
H-29b), 4.48 ( dd, $J=6.0 ; 12.0 \mathrm{~Hz}, \mathrm{H}-3$ ), 1.68, 1.03, 0.94, $0.88,0.85,0.84,0.79\left(21 \mathrm{H}, 7 \mathrm{~s}, 7 \mathrm{CH}_{3}\right)$.

${ }^{13} \mathrm{C} \mathrm{NMR}\left(\mathrm{CDCl}_{3}, 50 \mathrm{MHz}\right) \delta: 38.39\left(\mathrm{CH}_{2}, \mathrm{C}-1\right), 23.76$ $\left(\mathrm{CH}_{2}, \mathrm{C}-2\right), 80.63(\mathrm{C}, \mathrm{C}-3), 37.85(\mathrm{C}, \mathrm{C}-4), 55.39(\mathrm{CH}$, $\mathrm{C}-5), 18.22\left(\mathrm{CH}_{2}, \mathrm{C}-6\right), 34.22\left(\mathrm{CH}_{2}, \mathrm{C}-7\right), 40.87(\mathrm{C}, \mathrm{C}-8)$, 50.35 (CH, C-9), 37.10 (C, C-10), $20.96\left(\mathrm{CH}_{2}, \mathrm{C}-11\right)$, $25.11\left(\mathrm{CH}_{2}, \mathrm{C}-12\right), 38.01(\mathrm{CH}, \mathrm{C}-13), 42.84(\mathrm{C}, \mathrm{C}-14)$, $27.45\left(\mathrm{CH}_{2}, \mathrm{C}-15\right), 35.59\left(\mathrm{CH}_{2}, \mathrm{C}-16\right), 43.01(\mathrm{C}, \mathrm{C}-17)$ , 48.30 (C, CH-18), 48.32 (C, C-19), 150.98 (C, C-20), $29.84\left(\mathrm{CH}_{2}, \mathrm{C}-21\right), 40.02\left(\mathrm{CH}_{2}, \mathrm{C}-22\right), 27.99\left(\mathrm{CH}_{3}, \mathrm{C}-23\right)$, $16.59\left(\mathrm{CH}_{3}, \mathrm{C}-24\right), 16.19\left(\mathrm{CH}_{3}, \mathrm{C}-25\right), 15.99\left(\mathrm{CH}_{3}, \mathrm{C}-26\right)$, $14.54\left(\mathrm{CH}_{3}, \mathrm{C}-27\right), 18.02\left(\mathrm{CH}_{3}, \mathrm{C}-28\right), 109.38\left(\mathrm{CH}_{2}\right.$, C-29), $19.30\left(\mathrm{CH}_{3}, \mathrm{C}-30\right), 173.74(\mathrm{C}, \mathrm{C}-1$ ') $), 34.88\left(\mathrm{CH}_{2}\right.$, C-2'), $25.01\left(\mathrm{CH}_{2}, \mathrm{C}-3\right.$ ' $), 29.39\left(\mathrm{CH}_{2}, \mathrm{C}-4\right.$ '), $29.49\left(\mathrm{CH}_{2}\right.$, C-5'), $29.70\left(\mathrm{CH}_{2}, \mathrm{C}-6\right.$ '), $29.61\left(\mathrm{CH}_{2}, \mathrm{C}-7\right.$ '), $29.61\left(\mathrm{CH}_{2}\right.$, C-8'), $29.61\left(\mathrm{CH}_{2}, \mathrm{C}^{\prime} 9^{\prime}\right), 29.61\left(\mathrm{CH}_{2}, \mathrm{C}-10\right.$ ') $29.61\left(\mathrm{CH}_{2}\right.$, C-11'), $29.61\left(\mathrm{CH}_{2}, \mathrm{C}-12^{\prime}\right), 29.29\left(\mathrm{CH}_{2}, \mathrm{C}-13\right.$ '), 31.95 $\left(\mathrm{CH}_{2}, \mathrm{C}-14^{\prime}\right), 22.72\left(\mathrm{CH}_{2}, \mathrm{C}-15^{\prime}\right), 14.15\left(\mathrm{CH}_{3}, \mathrm{C}-16\right.$ ') CHN analysis: Calcd for $\mathrm{C}_{46} \mathrm{H}_{80} \mathrm{O}_{2}: \mathrm{C}, 83.07 ; \mathrm{H}, 12.12 \%$. Found: C, 83.25; H, 12.64\%.

Lupeol miristate (4): $636 \mathrm{~g} \mathrm{~mol}^{-1}$, [0.95 mmol (95\% yield)], (mp $\left.84.5-86.8^{\circ} \mathrm{C}\right)$.

IR $\left(\mathrm{KBr}, \mathrm{cm}^{-1}\right): 2953,2850(\mathrm{CH}), 1728(\mathrm{C}=\mathrm{O}), 1171(\mathrm{CO}-$ O-C), 881.

${ }^{1} \mathrm{H}$ NMR $\left(\mathrm{CDCl}_{3}, 200 \mathrm{MHz}\right) \delta: 4.57$ (s, H-29a), 4.68 (s, H-29b), 4.48 ( dd, $J=6.0 ; 12.0 \mathrm{~Hz}, \mathrm{H}-3$ ), 1.68, 1.03, 0.94, $0.91,0.88,0.84,0.79\left(21 \mathrm{H}, 7 \mathrm{~s}, 7 \mathrm{CH}_{3}\right)$.

${ }^{13} \mathrm{C}$ NMR $\left(\mathrm{CDCl}_{3}, 50 \mathrm{MHz}\right) \delta: 38.36\left(\mathrm{CH}_{2}, \mathrm{C}-1\right), 23.74$ $\left(\mathrm{CH}_{2}, \mathrm{C}-2\right), 80.61$ (C, C-3), $37.83(\mathrm{C}, \mathrm{C}-4), 55.37(\mathrm{CH}$, $\mathrm{C}-5), 18.20\left(\mathrm{CH}_{2}, \mathrm{C}-6\right), 34.20\left(\mathrm{CH}_{2}, \mathrm{C}-7\right), 40.84(\mathrm{C}, \mathrm{C}-8)$, 50.32 (CH, C-9), 37.08 (C, C-10), $20.93\left(\mathrm{CH}_{2}, \mathrm{C}-11\right)$, $25.08\left(\mathrm{CH}_{2}, \mathrm{C}-12\right), 38.03(\mathrm{CH}, \mathrm{C}-13), 42.82(\mathrm{C}, \mathrm{C}-14)$, $27.43\left(\mathrm{CH}_{2}, \mathrm{C}-15\right), 35.56\left(\mathrm{CH}_{2}, \mathrm{C}-16\right), 43.00(\mathrm{C}, \mathrm{C}-17)$, 48.28 (C, C-18), 48.01 (C, C-19), 150.98 (C, C-20), 29.83 $\left(\mathrm{CH}_{2}, \mathrm{C}-21\right), 40.00\left(\mathrm{CH}_{2}, \mathrm{C}-22\right), 27.97\left(\mathrm{CH}_{3}, \mathrm{C}-23\right), 16.58$ $\left(\mathrm{CH}_{3}, \mathrm{C}-24\right), 16.17\left(\mathrm{CH}_{3}, \mathrm{C}-25\right), 15.97\left(\mathrm{CH}_{3}, \mathrm{C}-26\right), 14.52$ $\left(\mathrm{CH}_{3}, \mathrm{C}-27\right), 18.00\left(\mathrm{CH}_{3}, \mathrm{C}-28\right), 109.36\left(\mathrm{CH}_{2}, \mathrm{C}-29\right)$, $19.28\left(\mathrm{CH}_{3}, \mathrm{C}-30\right), 173.74$ (C, C-1'), $34.87\left(\mathrm{CH}_{2}, \mathrm{C}-2\right.$ '), $25.18\left(\mathrm{CH}_{2}, \mathrm{C}-3\right.$ ') $), 29.48\left(\mathrm{CH}_{2}, \mathrm{C}-4\right.$ ') $29.37\left(\mathrm{CH}_{2}, \mathrm{C}-5\right.$ '), $29.65\left(\mathrm{CH}_{2}, \mathrm{C}-6\right.$ ' $), 29.60\left(\mathrm{CH}_{2}, \mathrm{C}-7\right.$ ' $), 29.60\left(\mathrm{CH}_{2}, \mathrm{C}-8\right.$ '), $29.60\left(\mathrm{CH}_{2}, \mathrm{C}-9^{\prime}\right), 29.60\left(\mathrm{CH}_{2}, \mathrm{C}-10^{\prime}\right), 29.27\left(\mathrm{CH}_{2}\right.$, C-11'), $31.93\left(\mathrm{CH}_{2}, \mathrm{C}-12^{\prime}\right), 22.70\left(\mathrm{CH}_{2}, \mathrm{C}-13^{\prime}\right), 14.14$ $\left(\mathrm{CH}_{2}, \mathrm{C}-14\right.$ ').

CHN analysis: Calcd for $\mathrm{C}_{44} \mathrm{H}_{76} \mathrm{O}_{2}: \mathrm{C}, 82.95 ; \mathrm{H}, 12.02 \%$. Found: C, 83.13; H, 12.49\%.

Lupeol laurate (5): $608 \mathrm{~g} \mathrm{~mol}^{-1}$, [0.89 mmol (89\% yield)], (mp $93.4-95.1^{\circ} \mathrm{C}$ ).

IR (ATR, $\left.\mathrm{cm}^{-1}\right)$ : 2923, 2853, 1727(C=O), $1176(\mathrm{CO}-\mathrm{O}-\mathrm{C})$, 877. 
${ }^{1} \mathrm{H}$ NMR $\left(\mathrm{CDCl}_{3}, 200 \mathrm{MHz}\right) \delta: 4.57(\mathrm{~s}, \mathrm{H}-29 \mathrm{a}), 4.68(\mathrm{~s}$, $\mathrm{H}-29 \mathrm{~b}), 4.47$ ( $\mathrm{m}, \mathrm{H}-3), 1.68,1.02,0.94,0.88,0.85, \mathrm{~b} 0.84$, $0.79\left(21 \mathrm{H}, 7 \mathrm{~s}, 7 \mathrm{CH}_{3}\right)$.

${ }^{13} \mathrm{C}$ NMR $\left(\mathrm{CDCl}_{3}, 50 \mathrm{MHz}\right) \delta: 38.37\left(\mathrm{CH}_{2}, \mathrm{C}-1\right), 23.75$ $\left(\mathrm{CH}_{2}, \mathrm{C}-2\right), 80.60(\mathrm{C}, \mathrm{C}-3), 37.83(\mathrm{C}, \mathrm{C}-4), 55.37(\mathrm{CH}$, $\mathrm{C}-5), 18.20\left(\mathrm{CH}_{2}, \mathrm{C}-6\right), 34.21\left(\mathrm{CH}_{2}, \mathrm{C}-7\right), 40.84(\mathrm{C}, \mathrm{C}-8)$, 50.33 (CH, C-9), 37.08 (C, C-10), $20.94\left(\mathrm{CH}_{2}, \mathrm{C}-11\right)$, $25.17\left(\mathrm{CH}_{2}, \mathrm{C}-12\right), 38.04(\mathrm{CH}, \mathrm{C}-13), 42.82(\mathrm{C}, \mathrm{C}-14)$, $27.43\left(\mathrm{CH}_{2}, \mathrm{C}-15\right), 35.57\left(\mathrm{CH}_{2}, \mathrm{C}-16\right), 43.00(\mathrm{C}, \mathrm{C}-17)$, 48.28 (CH, C-18), 48.01 (C, C-19), 150.94 (C, C-20), $29.82\left(\mathrm{CH}_{2}, \mathrm{C}-21\right), 40.00\left(\mathrm{CH}_{2}, \mathrm{C}-22\right), 27.97\left(\mathrm{CH}_{3}, \mathrm{C}-23\right)$, $16.57\left(\mathrm{CH}_{3}, \mathrm{C}-24\right), 16.17\left(\mathrm{CH}_{3}, \mathrm{C}-25\right), 15.97\left(\mathrm{CH}_{3}, \mathrm{C}-26\right)$, $14.52\left(\mathrm{CH}_{3}, \mathrm{C}-27\right), 18.00\left(\mathrm{CH}_{3}, \mathrm{C}-28\right), 109.37\left(\mathrm{CH}_{2}\right.$, $\mathrm{C}-29), 19.28\left(\mathrm{CH}_{3}, \mathrm{C}-30\right), 173.71$ (C, C-1'), $34.86\left(\mathrm{CH}_{2}\right.$, C-2'), $25.17\left(\mathrm{CH}_{2}, \mathrm{C}-3\right.$ ' $), 31.91\left(\mathrm{CH}_{2}, \mathrm{C}-4\right.$ '), $22.69\left(\mathrm{CH}_{2}\right.$, C-5'), $29.44\left(\mathrm{CH}_{2}, \mathrm{C}-6\right.$ '), $29.59\left(\mathrm{CH}_{2}, \mathrm{C}-7\right.$ ' $), 27.42\left(\mathrm{CH}_{2}\right.$, C-8'), $29.26\left(\mathrm{CH}_{2}, \mathrm{C}^{\prime} 9^{\prime}\right), 31.90\left(\mathrm{CH}_{2}, \mathrm{C}-10\right.$ '), $29.81\left(\mathrm{CH}_{2}\right.$, C-11'), $14.12\left(\mathrm{CH}_{2}, \mathrm{C}-12\right.$ ').

CHN analysis: Calcd for $\mathrm{C}_{42} \mathrm{H}_{72} \mathrm{O}_{2}$ : C, 82.83; H, 11.92\%. Found: C, 83.07; H, 13.09\%.

Lupeol caprate (6): $580 \mathrm{~g} \mathrm{~mol}^{-1}$, [0.92 mmol (92\% yield)], (mp $\left.92.5-93.8^{\circ} \mathrm{C}\right)$.

IR (ATR, $\left.\mathrm{cm}^{-1}\right)$ : 2928, 2851, 1728(C=O), 1175(CO-O-C), 881.

${ }^{1} \mathrm{H}$ NMR $\left(\mathrm{CDCl}_{3}, 200 \mathrm{MHz}\right) \delta: 4.57$ (s, H-29a), 4.68(s, $\mathrm{H}-29 \mathrm{~b}), 4.47$ ( $\mathrm{m}, \mathrm{H}-3), 1.68,1.02,0.94,0.88,0.85,0.84$, $0.79\left(21 \mathrm{H}, 7 \mathrm{~s}, 7 \mathrm{CH}_{3}\right)$.

${ }^{13} \mathrm{C}$ NMR $\left(\mathrm{CDCl}_{3}, 50 \mathrm{MHz}\right) \delta: 38.36\left(\mathrm{CH}_{2}, \mathrm{C}-1\right), 23.75$ $\left(\mathrm{CH}_{2}, \mathrm{C}-2\right), 80.60(\mathrm{C}, \mathrm{C}-3), 37.83(\mathrm{C}, \mathrm{C}-4), 55.37(\mathrm{CH}$, $\mathrm{C}-5), 18.20\left(\mathrm{CH}_{2}, \mathrm{C}-6\right), 34.20\left(\mathrm{CH}_{2}, \mathrm{C}-7\right), 40.84(\mathrm{C}, \mathrm{C}-8)$, $50.33(\mathrm{CH}, \mathrm{C}-9), 37.08$ (C, C-10), $20.94\left(\mathrm{CH}_{2}, \mathrm{C}-11\right)$, $25.17\left(\mathrm{CH}_{2}, \mathrm{C}-12\right), 38.04$ (CH, C-13), 42.82 (C, C-14), $27.43\left(\mathrm{CH}_{2}, \mathrm{C}-15\right), 35.57\left(\mathrm{CH}_{2}, \mathrm{C}-16\right), 43.00(\mathrm{C}, \mathrm{C}-17)$, 48.28 (CH, C-18), 48.00 (C, C-19), 150.94 (C, C-20), $29.82\left(\mathrm{CH}_{2}, \mathrm{C}-21\right), 40.00\left(\mathrm{CH}_{2}, \mathrm{C}-22\right), 27.97\left(\mathrm{CH}_{3}, \mathrm{C}-23\right)$, $16.57\left(\mathrm{CH}_{3}, \mathrm{C}-24\right), 16.17\left(\mathrm{CH}_{3}, \mathrm{C}-25\right), 15.97\left(\mathrm{CH}_{3}, \mathrm{C}-26\right)$, $14.52\left(\mathrm{CH}_{3}, \mathrm{C}-27\right), 18.00\left(\mathrm{CH}_{3}, \mathrm{C}-28\right), 109.36\left(\mathrm{CH}_{2}\right.$, C-29), $19.28\left(\mathrm{CH}_{3}, \mathrm{C}-30\right), 173.70$ (C, C-1'), 34.87( $\mathrm{CH}_{2}$, C-2'), $25.17\left(\mathrm{CH}_{2}, \mathrm{C}^{\prime} 3^{\prime}\right), 29.26\left(\mathrm{CH}_{2}, \mathrm{C}-4\right.$ ' $), 29.19\left(\mathrm{CH}_{2}\right.$, C-5'), $29.43\left(\mathrm{CH}_{2}, \mathrm{C}-6\right.$ ' $), 29.43\left(\mathrm{CH}_{2}, \mathrm{C}-7^{\prime}\right), 31.86\left(\mathrm{CH}_{2}\right.$, C-8'), $29.82\left(\mathrm{CH}_{2}, \mathrm{C}-9\right.$ ') $14.11\left(\mathrm{CH}_{2}, \mathrm{C}-10{ }^{\prime}\right)$.

CHN analysis: Calcd for $\mathrm{C}_{40} \mathrm{H}_{68} \mathrm{O}_{2}: \mathrm{C}, 82.69 ; \mathrm{H}, 11.80 \%$. Found: $\mathrm{C}, 82.77 ; \mathrm{H}, 13.03 \%$.

Lupeol caprilate (7): $552 \mathrm{~g} \mathrm{~mol}^{-1}$, [0.96 mmol (96\% yield)], (mp $\left.145.0-145.7^{\circ} \mathrm{C}\right)$.

IR $\left(\mathrm{KBr}, \mathrm{cm}^{-1}\right)$ : $1727(\mathrm{C}=\mathrm{O}) ; 1179(\mathrm{CO}-\mathrm{O}-\mathrm{C}), 2927,2852$ $(\mathrm{CH})$.

${ }^{1} \mathrm{H}$ NMR $\left(\mathrm{CDCl}_{3}, 200 \mathrm{MHz}\right) \delta: 4.57$ (s, H-29a), 4.68(s, H-29b), 4.48 (dd, $J=6.0 ; 8.0$ Hz, H-3), 1.68, 1.03, 0.94,
0.87, 0.85, 0.84, $0.79\left(\mathrm{~s}, 21 \mathrm{H}, 7 \mathrm{~s}, 7 \mathrm{CH}_{3}\right)$.

${ }^{13} \mathrm{C}$ NMR $\left(\mathrm{CDCl}_{3}, 50 \mathrm{MHz}\right) \delta: 38.36\left(\mathrm{CH}_{2}, \mathrm{C}-1\right), 23.73$ $\left(\mathrm{CH}_{2}, \mathrm{C}-2\right), 80.60(\mathrm{C}, \mathrm{C}-3), 38.02(\mathrm{C}, \mathrm{C}-4), 55.36(\mathrm{CH}$, $\mathrm{C}-5), 18.19\left(\mathrm{CH}_{2}, \mathrm{C}-6\right), 34.20\left(\mathrm{CH}_{2}, \mathrm{C}-7\right), 40.83(\mathrm{C}, \mathrm{C}-8)$, $50.32(\mathrm{CH}, \mathrm{C}-9), 37.07$ (C, C-10), $20.93\left(\mathrm{CH}_{2}, \mathrm{C}-11\right)$, $25.16\left(\mathrm{CH}_{2}, \mathrm{C}-12\right), 38.02(\mathrm{CH}, \mathrm{C}-13), 42.82(\mathrm{C}, \mathrm{C}-14)$, $27.42\left(\mathrm{CH}_{2}, \mathrm{C}-15\right), 35.56\left(\mathrm{CH}_{2}, \mathrm{C}-16\right), 42.98(\mathrm{C}, \mathrm{C}-17)$, 48.27 (CH, C-18), 48.00 (C, C-19), 150.95 (C, C-20), $29.81\left(\mathrm{CH}_{2}, \mathrm{C}-21\right), 40.83\left(\mathrm{CH}_{2}, \mathrm{C}-22\right), 27.95\left(\mathrm{CH}_{3}, \mathrm{C}-23\right)$, $16.56\left(\mathrm{CH}_{3}, \mathrm{C}-24\right), 16.16\left(\mathrm{CH}_{3}, \mathrm{C}-25\right), 15.96\left(\mathrm{CH}_{3}, \mathrm{C}-26\right)$, $14.51\left(\mathrm{CH}_{3}, \mathrm{C}-27\right), 18.19\left(\mathrm{CH}_{3}, \mathrm{C}-28\right), 109.35\left(\mathrm{CH}_{2}\right.$, $\mathrm{C}-29), 19.27\left(\mathrm{CH}_{3}, \mathrm{C}-30\right), 173.70(\mathrm{C}, \mathrm{C}-1$ ' $), 34.85\left(\mathrm{CH}_{2}\right.$, C-2'), $25.16\left(\mathrm{CH}_{2}, \mathrm{C}-3^{\prime}\right), 29.13\left(\mathrm{CH}_{2}, \mathrm{C}-4^{\prime}\right), 29.13\left(\mathrm{CH}_{2}\right.$, C-5'), $31.67\left(\mathrm{CH}_{2}, \mathrm{C}-6\right.$ '), $22.59\left(\mathrm{CH}_{2}, \mathrm{C}-7^{\prime}\right), 14.06\left(\mathrm{CH}_{2}\right.$, C-8').

CHN analysis: Calcd for $\mathrm{C}_{38} \mathrm{H}_{64} \mathrm{O}_{2}: \mathrm{C}, 82.55 ; \mathrm{H}, 11.67 \%$. Found: C, 82.68; H, 12.96\%.

Lupeol caproate $(\mathbf{8})$ : $524 \mathrm{~g} \mathrm{~mol}^{-1}$, [0.87 mmol (87\% yield)], (mp $\left.156.4-159.7^{\circ} \mathrm{C}\right)$.

IR $\left(\mathrm{KBr}, \mathrm{cm}^{-1}\right)$ : 2936, 2858, 1727(C=O), $1180(\mathrm{CO}-\mathrm{O}-\mathrm{C})$, 877.

${ }^{1} \mathrm{H}$ NMR $\left(\mathrm{CDCl}_{3}, 200 \mathrm{MHz}\right) \delta: 4.58(\mathrm{~d}, \mathrm{~J}=2.0 \mathrm{~Hz}, \mathrm{H}-29 \mathrm{a})$, 4.68 (d, J=2.0Hz, H-29b), 4.47 ( dd, $J=4.0 ; 6.0 \mathrm{~Hz}, \mathrm{H}-3$ ), $1.68,1.03,0.94,0.85,0.84,0.83,0.79\left(21 \mathrm{H}, 7 \mathrm{~s}, 7 \mathrm{CH}_{3}\right)$

${ }^{13} \mathrm{C} \mathrm{NMR}\left(\mathrm{CDCl}_{3}, 50 \mathrm{MHz}\right) \delta: 38.37\left(\mathrm{CH}_{2}, \mathrm{C}-1\right), 23.74$ $\left(\mathrm{CH}_{2}, \mathrm{C}-2\right), 80.62(\mathrm{C}, \mathrm{C}-3), 37.83(\mathrm{C}, \mathrm{C}-4), 55.37(\mathrm{CH}$, $\mathrm{C}-5), 18.20\left(\mathrm{CH}_{2}, \mathrm{C}-6\right), 34.21\left(\mathrm{CH}_{2}, \mathrm{C}-7\right), 40.85(\mathrm{C}, \mathrm{C}-8)$, 50.33 (CH, C-9), 37.08 (C, C-10), $20.94\left(\mathrm{CH}_{2}, \mathrm{C}-11\right)$, $25.09\left(\mathrm{CH}_{2}, \mathrm{C}-12\right), 38.04$ (CH, C-13), 42.83 (C, C-14), $27.43\left(\mathrm{CH}_{2}, \mathrm{C}-15\right), 35.57\left(\mathrm{CH}_{2}, \mathrm{C}-16\right), 42.99(\mathrm{C}, \mathrm{C}-17)$, 48.28 (CH, C-18), 48.00 (C, C-19), 150.95 (C, C-20), $29.83\left(\mathrm{CH}_{2}, \mathrm{C}-21\right), 39.99\left(\mathrm{CH}_{2}, \mathrm{C}-22\right), 27.96\left(\mathrm{CH}_{3}, \mathrm{C}-23\right)$, $16.56\left(\mathrm{CH}_{3}, \mathrm{C}-24\right), 16.17\left(\mathrm{CH}_{3}, \mathrm{C}-25\right), 15.97\left(\mathrm{CH}_{3}, \mathrm{C}-26\right)$, $14.52\left(\mathrm{CH}_{3}, \mathrm{C}-27\right), 18.00\left(\mathrm{CH}_{3}, \mathrm{C}-28\right), 109.36\left(\mathrm{CH}_{2}\right.$, $\mathrm{C}-29), 19.28\left(\mathrm{CH}_{3}, \mathrm{C}-30\right), 173.71\left(\mathrm{C}, \mathrm{C}-1^{\prime}\right), 34.81\left(\mathrm{CH}_{2}\right.$, C-2'), $24.83\left(\mathrm{CH}_{2}, \mathrm{C}-3\right.$ '), $31.33\left(\mathrm{CH}_{2}, \mathrm{C}-4\right.$ '), $22.32\left(\mathrm{CH}_{2}\right.$, $\left.\mathrm{C}-5^{\prime}\right), 13.92\left(\mathrm{CH}_{3}, \mathrm{C}-6\right.$ ')

CHN analysis: Calcd for $\mathrm{C}_{36} \mathrm{H}_{60} \mathrm{O}_{2}$ : C, 82.38; $\mathrm{H}, 11.52 \%$. Found: $\mathrm{C}, 82.66 ; \mathrm{H}, 12.72 \%$.

Lupeol 3',4'-dimethoxybenzoate (9): 590 g. $\mathrm{mol}^{-1}$, [0.90 mmol $(90 \%$ yield $)],\left(\mathrm{mp} 243.6-245.3{ }^{\circ} \mathrm{C}\right)$.

IR (KBr, cm $\left.{ }^{-1}\right)$ : 2944, 2857, 1704, 1267, 1247, 968, 761. ${ }^{1} \mathrm{H} \mathrm{NMR}\left(\mathrm{CDCl}_{3}, 200 \mathrm{MHz}\right) \delta: 7.70$ (d, J=10.0 Hz, H-6' $)$, 7.56 (s, H-2'), 6.90 (d, J=8.0Hz, H-5') 4.69 (t, H-29a,b), 4.58 (s, H-3), 3.93 (s, H-9', H-10'), 1.68, 1.05, 0.99, 0.97, $0.92,0.90,0.80\left(21 \mathrm{H}, 7 \mathrm{~s}, 7 \mathrm{CH}_{3}\right)$.

${ }^{13} \mathrm{C}$ NMR $\left(\mathrm{CDCl}_{3}, 50 \mathrm{MHz}\right) \delta: 38.40\left(\mathrm{CH}_{2}, \mathrm{C}-1\right)$, 25.11( $\left.\mathrm{CH}_{2}, \mathrm{C}-2\right), 81.38$ (C, C-3), 38.22 (C, C-4), 55.44 $(\mathrm{CH}, \mathrm{C}-5), 18.24\left(\mathrm{CH}_{2}, \mathrm{C}-6\right), 34.22\left(\mathrm{CH}_{2}, \mathrm{C}-7\right), 40.88$ 
(C, C-8), $50.36(\mathrm{CH}, \mathrm{C}-9), 37.14(\mathrm{C}, \mathrm{C}-10), 20.98\left(\mathrm{CH}_{2}\right.$, $\mathrm{C}-11), 23.83\left(\mathrm{CH}_{2}, \mathrm{C}-12\right), 38.06(\mathrm{CH}, \mathrm{C}-13), 42.86$ (C, $\mathrm{C}-14), 27.45\left(\mathrm{CH}_{2}, \mathrm{C}-15\right), 35.58\left(\mathrm{CH}_{2}, \mathrm{C}-16\right), 43.00(\mathrm{C}$, C-17), 48.29 (CH, C-18), 48.02 (C, C-19), 150.95 (C, $\mathrm{C}-20), 29.84\left(\mathrm{CH}_{2}, \mathrm{C}-21\right), 40.01\left(\mathrm{CH}_{2}, \mathrm{C}-22\right), 28.14\left(\mathrm{CH}_{3}\right.$, $\mathrm{C}-23), 16.01\left(\mathrm{CH}_{3}, \mathrm{C}-24\right), 16.81\left(\mathrm{CH}_{3}, \mathrm{C}-25\right), 16.20\left(\mathrm{CH}_{3}\right.$, $\mathrm{C}-26), 14.56\left(\mathrm{CH}_{3}, \mathrm{C}-27\right), 18.02\left(\mathrm{CH}_{3}, \mathrm{C}-28\right), 109.38$ $\left(\mathrm{CH}_{2}, \mathrm{C}-29\right), 19.30\left(\mathrm{CH}_{3}, \mathrm{C}-30\right), 166.10\left(\mathrm{C}, \mathrm{C}-1^{\prime}\right), 152.79$ (C, C-2'), 112.03 (CH, C-3'), 148.59 (C, C-4'), 150.95 (C, C-5'), 110.21 (CH, C-6'), 123.35 (CH, C-7'), $55.94\left(\mathrm{CH}_{3}\right.$, C-8'), $55.94\left(\mathrm{CH}_{3}, \mathrm{C}-9\right.$ ').

CHN analysis: Calcd for $\mathrm{C}_{39} \mathrm{H}_{58} \mathrm{O}_{4}$ : C, 79.28; $\mathrm{H}, 9.89 \%$. Found: C, 79.33; H, 10.56\%.

XRD analysis of compound 1 revealed its needle shape and established a structure in which the carbon atoms distribution (Figure 2) is in accordance with the ${ }^{13} \mathrm{C}$ NMR data.

For the XRD experiments, the material was homogenously spread over the sample holder under spinning to prevent preferred orientation and minimize rugosity effects over the exposed surface. The small amount submitted to the XRD, few milligrams, was composed essentially of polycrystalline material. Single crystals were not identified or isolated from the synthetic material. So, detailed crystallographic data were provided only for the isolated lupeol. For lupeol (1), the angles are 90.0 due to the special positions on tetragonal P43 space group symmetric restrictions. Other details of refinements and X-ray diffraction experimental data are summarized in Table I. Due to the small amount of esters ( 2 to 9 ), all fittings were obtained at P-1 space group that safely allowed us to index all peaks. After extracting and fitting, all peaks in space group P-1 were searched for more symmetric space group based on the Bragg systematic absences. More symmetric space groups were achieved for compounds $\mathbf{1 , 7}$ and $\mathbf{8}$. The remaining ones have not shown any symmetric description based on the systematic Bragg absences. The powder XRD data of lupeol esters 2 to 9 (Table I) were consistent with the ${ }^{13} \mathrm{C}$ NMR data of each one indicating the tendency of the compounds to be in the crystalline state. The XRD experiment was considered as an excellent tool to determine the structure of lupeol and its esters in solid state.

\section{Cell proliferation assays}

All the compounds were tested for proliferation of human cancer cells. Doxorubicin (anthracycline) used as positive control is a chemotherapy drug that decreases or stops the growth of cancer cells. The activity of doxorubicin involves blocking the enzyme called topo isomerase 2 that cancer cells need to replicate and grow. Lupeol was inactive $\left(\mathrm{GI}_{50}>250 \mu \mathrm{g} / \mathrm{mL}\right)$ in the experimental condition while lupeol esters 2-4 and 7-9 showed a cytostatic effect on colorectal adenocarcinoma (HT-29) and chronic myelogenous leukemia (K-562) cell lines (Table II).

The introduction of a long alkyl side chain (2) in lupeol resulted in a cytostatic effect on the colorectal adenocarcinoma (HT29) cell line $\left(\mathrm{GI}_{50}=97.81 \mu \mathrm{g} / \mathrm{mL}\right)$. This effect increased by reducing the length of the alkyl chain, from $\mathrm{C} 16$ (2) to $\mathrm{C} 12$ (4), resulting in the best effect $\left(\mathrm{GI}_{50}=1.74 \mu \mathrm{g} / \mathrm{mL}\right)$. However, the continuous
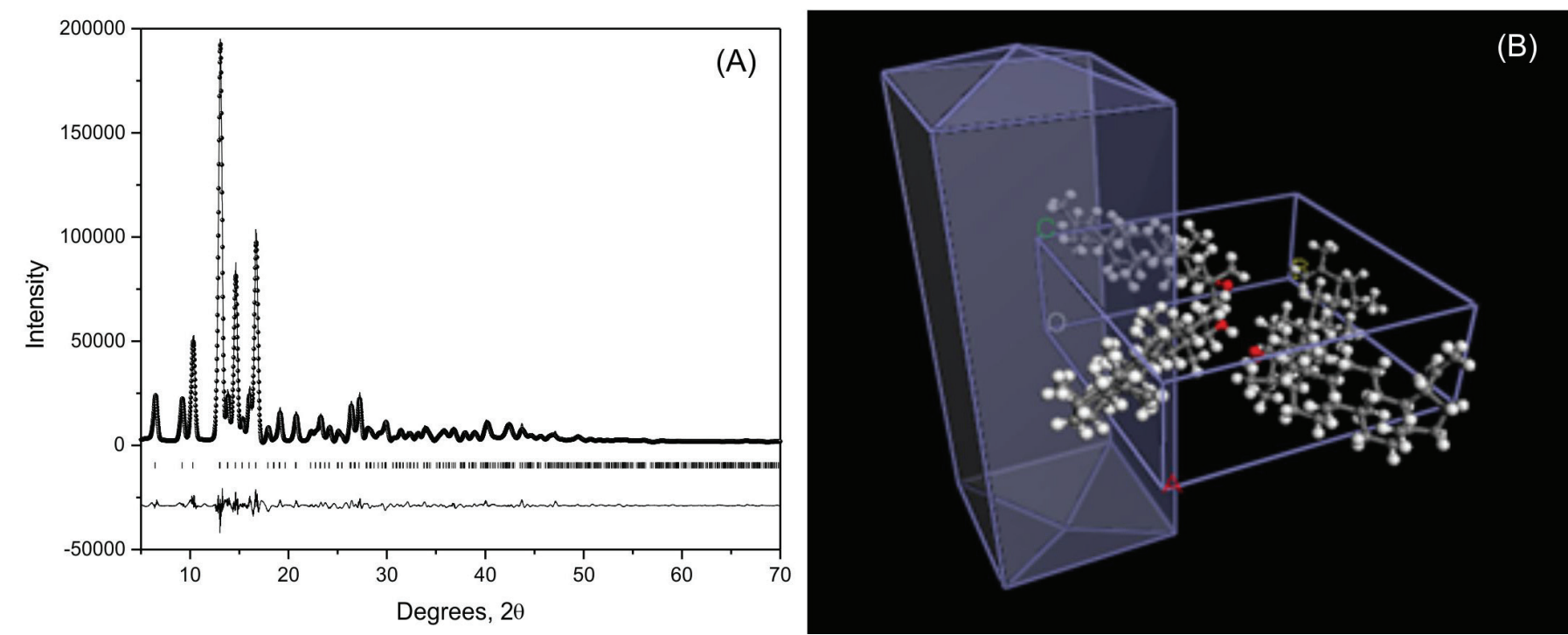

FIGURE 2 - Powder X-ray diffraction (XRD) data: (A) lupeol difratogram; (B) lupeol chemical structure, found in solid with a needle shape. 
A. T. M. Silva, C. G. Magalhães, L. P. Duarte, W. N. Mussel, A. L. T. G. Ruiz, L. Shiozawa, J. E. Carvalho, I. C. Trindade, S, A, Vieira Filho

TABLE I - Lupeol (1) and its esters ( 2 to 9 ) lattice parameters obtained by Rietveld fitting of the powder X-ray diffraction

\begin{tabular}{cccccccc}
\hline Compounds & $\boldsymbol{a}(\mathbf{n m})$ & $\boldsymbol{b}(\mathbf{n m})$ & $\boldsymbol{c}(\mathbf{n m})$ & $\left.\alpha \boldsymbol{(}^{(}\right)$ & $\beta\left(^{(}\right)$ & $\gamma\left(\mathbf{(}^{0}\right)$ & Space Group \\
\hline $\mathbf{1}$ & $19.513 \pm 0.005$ & $19.513 \pm 0.005$ & $7.383 \pm 0.002$ & 90.0 & 90.0 & 90.0 & $\mathrm{P} 43$ \\
$\mathbf{2}$ & $*$ & $*$ & $*$ & $*$ & $*$ & $*$ & $*$ \\
$\mathbf{3}$ & $7.37 \pm 0.04$ & $16.8 \pm 0.1$ & $17.1 \pm 0.1$ & $98.64 \pm 0.01$ & $106.41 \pm 0.01$ & $90.35 \pm 0.01$ & $\mathrm{P}-1$ \\
$\mathbf{4}$ & $7.68 \pm 0.01$ & $11.08 \pm 0.01$ & $14.55 \pm 0.01$ & $89.30 \pm 0.01$ & $83.82 \pm 0.01$ & $77.33 \pm 0.01$ & $\mathrm{P}-1$ \\
$\mathbf{5}$ & $6.98 \pm 0.07$ & $8.73 \pm 0.09$ & $9.8 \pm 0.1$ & $87.52 \pm 0.03$ & $88.33 \pm 0.02$ & $89.12 \pm 0.03$ & $\mathrm{P}-1$ \\
$\mathbf{6}$ & $9.56 \pm 0.01$ & $11.32 \pm 0.01$ & $21.22 \pm 0.01$ & $102.63 \pm 0.01$ & $95.65 \pm 0.01$ & $92.66 \pm 0.01$ & $\mathrm{P}-1$ \\
$\mathbf{7}$ & $8.03 \pm 0.02$ & $18.55 \pm 0.06$ & $12.74 \pm 0.04$ & 90.0 & $96.68 \pm 0.01$ & 90.0 & $\mathrm{P} 121$ \\
$\mathbf{8}$ & $25.3 \pm 0.2$ & $8.15 \pm 0.06$ & $21.6 \pm 0.2$ & 90.0 & $119.63 \pm 0.02$ & 90.0 & $\mathrm{C} 121$ \\
$\mathbf{9}$ & $10.39 \pm 0.06$ & $11.60 \pm 0.06$ & $13.92 \pm 0.07$ & $98.50 \pm 0.01$ & $91.80 \pm 0.01$ & $105.87 \pm 0.01$ & $\mathrm{P}-1$ \\
\hline
\end{tabular}

TABLE II - Concentration ( $\mu \mathrm{g} / \mathrm{mL})$ of lupeol (1) and its esters (2 - 9) necessary to inhibit $50 \%$ cell growth $\left(\mathrm{GI}_{50}\right)$

\begin{tabular}{ccccccccc}
\hline \multirow{2}{*}{$\begin{array}{c}\text { Compound } \\
\text { tested }\end{array}$} & U251 & $\begin{array}{c}\text { NCI-ADR/ } \\
\text { RES }\end{array}$ & $\mathbf{7 8 6 - 0}$ & NCI-H460 & PC-3 & OVCAR-03 & HT29 & K562 \\
\hline Doxo & $<0.025$ & 25 & 0.038 & $<0.025$ & 0.025 & 0.23 & 0.026 & $>25$ \\
$\mathbf{1}$ & $*$ & $*$ & $*$ & $*$ & $*$ & $*$ & $*$ & $*$ \\
$\mathbf{2}$ & $*$ & $*$ & $*$ & $*$ & $*$ & $*$ & 97.81 & 0.35 \\
$\mathbf{3}$ & $*$ & $*$ & $*$ & 250 & $*$ & $*$ & 35.94 & $<0.25$ \\
$\mathbf{4}$ & $*$ & $*$ & $*$ & $*$ & $*$ & $*$ & 1.74 & 0.41 \\
$\mathbf{5}$ & $*$ & $*$ & $*$ & $*$ & $*$ & $*$ & $*$ & $*$ \\
$\mathbf{6}$ & $*$ & $*$ & $*$ & $*$ & $*$ & $*$ & $*$ & $*$ \\
$\mathbf{7}$ & $*$ & $*$ & $*$ & $*$ & $*$ & $*$ & $*$ & $<0.25$ \\
$\mathbf{8}$ & $*$ & $*$ & $*$ & $*$ & $*$ & $*$ & 250 & $<0.25$ \\
$\mathbf{9}$ & $*$ & $*$ & $*$ & $*$ & $*$ & $*$ & 0.95 & $<0.25$ \\
\hline
\end{tabular}

Key: ${ }^{*}=\mathrm{GI}_{50}>250 \mu \mathrm{g} / \mathrm{mL}$; Doxo, doxorubicine (positive control); 33-Lup-20(29)-en-3-ol (lupeol) (1); lupeol stearate (2); lupeol palmitate (3); lupeol miristate (4); lupeol laurate (5); lupeol caprate (6); lupeol caprilate (7); lupeol caproate (8); lupeol 3',4'-dimethoxybenzoate (9). Human tumor cell lines: U251 (glioma), NCI-ADR/RES (ovarian expressing the resistance phenotype for adryamycin), 786-0 (kidney), NCI-H460 (lung, non-small cells), PC-3 (prostate), OVCAR-03 (ovarian), HT-29 (colon), and K-562 (chronic myelogenous leukemia).

reduction in the chain length (from $\mathrm{C} 10$ to $\mathrm{C} 4$, compounds 5-8) afforded inactive compounds $\left(\mathrm{GI}_{50}>250 \mu \mathrm{g} / \mathrm{mL}\right)$. Moreover, lupeol palmitate (3) showed a selective growth inhibition effect on erythromyeloblastoid leukemia (K-562) cells in a concentration-dependent way (Figure S2). Previous studies have shown that the palmitic acid is active against leukemic cells (Harada et al., 2002). Probably, the activity observed for lupeol palmitate is due to the fatty moiety. Thus, compound 3 could be considered as a prototype for the development of new anticancer drugs to be used in leukemia treatment. For the aryl lupeol ester (9) it was seen a quite similar cytostatic effect $\left(\mathrm{GI}_{50}=0.95 \mu \mathrm{g} / \mathrm{mL}\right)$ to that observed for ester 4. On the other hand, the side chain length seemed not to be as influent against chronic myelogenous leukemia (K-562) cells as for antiproliferative activity against HT29. In this regard, only compounds $\mathbf{5}$ (with ten carbon in side chain) and $\mathbf{6}$ (with eight carbons in side chain) were not able to inhibit K-562 cell proliferation up to $250 \mu \mathrm{g} /$ $\mathrm{mL}$ (Figure S2, Table II). The esters 4 and $\mathbf{9}$ showed a selective cytostatic effect with low $\mathrm{GI}_{50}$ values (Figure S2), therefore, these compounds represent a promising prototype for the development of new anticancer drugs.

For the aryl lupeol ester (9) it was seen a quite similar cytostatic effect $\left(\mathrm{GI}_{50}=0.95 \mu \mathrm{g} / \mathrm{mL}\right)$ than observed for ester 4. 


\section{CONCLUSION}

The esters 2 to 9 were obtained using lupeol, an adequate carboxylic acid and DIC/DMAP reagents, with yields ranging from 86 to $96 \%$. The esters 5 to 9 were new compounds. The XDR method was an excellent tool to determine the structure of lupeol and its esters in solid state. Lupeol esters 3, 4 and $\mathbf{9}$ showed a selective cytostatic effect with low $\mathrm{GI}_{50}$ values, representing a promising prototype for the development of new anticancer drugs.

\section{EXPERIMENTAL SECTION}

\section{General experimental procedures}

Melting points ( $\mathrm{mp}$ ) (uncorrected) were determined using a Mettler FP $80 \mathrm{HT}$ apparatus. ${ }^{13} \mathrm{C}$ NMR spectra were obtained on a Bruker Avance DRX 400 or on Bruker DPX 200 spectrometers. The sample was dissolved in $\mathrm{CDCl}_{3}$ and TMS was used as internal standard $\left(\delta_{\mathrm{C}}=0\right)$. IR spectra were recorded on a FITR-Perkin-Elmer, Spectrum One SN 74759 spectrophotometer. Powder X-ray diffraction (XRD) data were collected in an XRD-7000 diffractometer (Shimadzu, Japan) under $40 \mathrm{kV}, 30 \mathrm{~mA}$, using $\mathrm{Cu} \mathrm{K} \alpha(\lambda$ $=1.54056 \AA$ ) equipped with a polycapillary focusing optics under parallel geometry coupled with a graphite monochromator, scanned over an angular range of $4-70^{\circ}$ $(2 \theta)$ with a step size of $0.01^{\circ}(2 \theta)$ and a time constant of 5 s.step ${ }^{-1}$. The sample holder was submitted to a spinning of 30 cycles per minute to minimize rugosity effects and to reduce any eventual preferred orientation. The lattice parameters were extracted and fitted by Rietveld fitting analysis. $\mathrm{CHN}$ analyses were performed in a Perkin Elmer, Series II, CHNS/O Analyzer. Classical chromatographic column (CC) was carried out using silica gel 60 (Merck, 70-230 Mesh). TLC was obtained using pre-coated silica gel plates, and the detection was visualized by spraying the plates with solution (1:1) of vanillin (ethanol $1 \%$ solution $\mathrm{w} / \mathrm{v}$ ) in perchloric acid ( $3 \%$ aqueous solution $\mathrm{v} / \mathrm{v}$ ), in accordance with Wagner and Bladt (1996).

\section{Plant material}

Maytenus salicifolia Reissek (Celastraceae) was collected at 'Serra de Ouro Branco', a mountain located in the Ouro Branco City region, Minas Gerais (MG) state, Brazil. The plant was identified by Dr. Rita Maria CarvalhoOkano, Botanist of the Universidade Federal de Viçosa, MG, Brazil. A voucher specimen of M. salicifolia was deposited (N. OUPR-18094) at the Herbarium José Badini of the Universidade Federal de Ouro Preto, MG, Brazil.

\section{Isolation of lupeol and synthesis of esters}

The isolation of lupeol was reported by Magalhães and coworkers (2011). For the esters synthesis, the following sequence was carried out for the reactions: to 1.0 mmol of lupeol (1), $\mathbf{x}$ mmol of carboxylic acid and $\mathbf{y} \mathrm{mmol}$ of 4-(dimethylamino)pyridine (DMAP) in $7.0 \mathrm{~mL}$ of dry dichloromethane were added (Table I). After cooling down to $0{ }^{\circ} \mathrm{C}$ and under constant magnetic stirring, $\mathbf{z}$ mmol of $N, N^{\star}$-diisopropylcarbodiimide (DIC) was carefully added. Then, the reaction mixture was maintained under magnetic stirring, at room temperature, for 2 to 48 hours depending on the carboxylic acid used as reagent. The reaction time was monitored by TLC using $\mathrm{CHCl}_{3}-\mathrm{MeOH}(9.5: 0.5)$ as mobile phase. The reaction conditions of carboxylic acid with lupeol [1, (1.0 mmol)] and DIC/DMAP to obtain the lupeol esters 2 to 9 (Figure 1) are presented in Table SI.

At the end of the reaction, the dichloromethane was recovered in a rotator evaporator and the residual material obtained from each esterification reaction was purified by chromatographic column eluted with $\mathrm{CHCl}_{3}$. The lupeol esters 2 to 4 (Figure 1) were obtained as a white waxy material while lupeol esters 5 to 9 were obtained as a white amorphous solid.

\section{Characterization of compounds}

The structure of lupeol and its synthesized esters were initially characterized by IR, NMR $\left({ }^{1} \mathrm{H},{ }^{13} \mathrm{C}\right)$ and $\mathrm{CHN}$ data. The spectral results were carefully compared with data available in the literature (Mahato, Kundu, 1994). Then, the structure of each compound was fitted through powder XRD. Thus, compound $\mathbf{1}$ (or ester $\mathbf{2}$ to 9) was reduced to a very fine powder and deposited as a film suspension in a Zero Field Sample Holder (ZFSH) composed by polished $\mathrm{SiC}$ in a $3^{\circ}$ angle mount to reduce background contributions for the X-ray diffraction experiment. The powder indexing tool used was Conograph (Oishi-Tomiyasu, 2012) for cell and space group determination, followed by Pareto optimization and Rietveld with energies fitting of the structure. The peaks were searched and fitted with a David-Voight approximation peak profile, performing both modified Pawley and Rietveld with energy refinements to optimize powder diffraction parameters and crystal structure, so that the best possible agreement between simulated and experimental powder pattern was achieved. Lattice parameters were expressed in nanometers $(\mathrm{nm})$ and the angles in degrees (0). The fitted uncertainties were listed with the significant figures obtained. Due to the 
small amount of material (lupeol esters), all fittings were obtained at P-1 space group, which allowed us to index all peaks safely. To search for more symmetric Space Group occurrences more natural extracted material would be necessary to increase low intensity peaks that may help search for more symmetry in all diffractograms. After extracting and fitting all peaks in space group P-1, a search was performed for more symmetric space groups based on the Bragg systematic absences. Details of refinements and experimental data of X-ray diffraction are summarized in Table I.

\section{Antiproliferative activity}

\section{Human cell lines}

Eight human tumor cell lines were used: U-251 (glioma), NCI-ADR/RES (ovarian expressing the resistance phenotype for adryamycin), 786-0 (kidney), NCI-H460 (lung, non-small cells), PC-3 (prostate), OVCAR-03 (ovarian), HT-29 (colon), and K-562 (erythromyeloblastoid leukemia). The eight human tumor cell lines were provided by the Frederick Cancer Research \& Development Center, National Cancer Institute, Frederick, MA, USA. The cells were grown in RPMI 1640 Medium (GIBCO BRL) supplemented with 5\% fetal bovine serum (FBS) (GIBCO BRL) and penicillin/ streptomycin mixture $(1000 \mathrm{U} / \mathrm{mL}: 1000 \mu \mathrm{g} / \mathrm{mL}, 1.0 \mathrm{~mL} / \mathrm{L}$ $\mathrm{RPMI})$ at $37^{\circ} \mathrm{C}$ in a $5 \% \mathrm{CO}_{2}$ atmosphere.

\section{Sample preparation}

Aliquots (5.0 mg) of lupeol and its esters 2 to 9 were initially diluted in DMSO $(50 \mu \mathrm{L})$ followed by the addition of $950 \mu \mathrm{L}$ of RPMI 1640/FBS 5\% (working solution). The solutions were then diluted in RPMI 1640/FBS 5\% in order to obtain the final concentrations. DMSO final concentrations $(\leq 0.25 \%)$ in culture medium did not affect the cell viability.

\section{Antiproliferative assay}

Cells in 96-well microplates $(100 \mu \mathrm{L}$ cells/well, inoculation density from 3 to $7 \times 10^{4}$ cell $\left./ \mathrm{mL}\right)$ were exposed for $48 \mathrm{~h}$ to crescent concentrations $(0.25,2.5$, 25.0 , and $250.0 \mu \mathrm{g} / \mathrm{mL}$, in triplicate) of $\mathbf{1}$ and its esters 2 to 9 at $37{ }^{\circ} \mathrm{C}$ in a $5 \% \mathrm{CO}_{2}$ atmosphere. Doxorubicin chloridrate $(0.1 \mathrm{mg} / \mathrm{mg}$; Europharma) was used as positive control $(0.025,0.25,2.5$ and $25 \mu \mathrm{g} / \mathrm{ml})$. Before (T0 plate) and after sample addition (T1 plates), cells were fixed with $50 \%$ trichloroacetic acid $(50 \mu \mathrm{L} /$ well $)$. Cellular proliferation was determined by the spectrophotometric quantification $(540 \mathrm{~nm})$ of cellular protein content using sulforhodamine B assay (Monks et al., 1991). Using the concentration-response curve for each cell line, $\mathrm{GI}_{50}$ (concentration that inhibits cell growth by $50 \%$ ) was determined through non-linear regression analysis using the software ORIGIN 8.0 (Origin Lab Corporation) (Dos Santos et al., 2015; Da Silva et al., 2015).

\section{ACKNOWLEDGEMENTS}

The authors thank the Conselho Nacional de Desenvolvimento Científico e Tecnológico (CNPq) and Fundação de Amparo à Pesquisa de Minas Gerais (FAPEMIG) for financial support.

\section{REFERENCES}

Andrikopoulos NK, Kaliora AC, Assimopoulou AN, Papapeorgiou VP. Biological activity of some naturally occurring resins, gums and pigments against in vitro LDL oxidation. Phytother Res. 2003;17(5):501-507.

Chabner BA, Roberts Jr TG. Chemotherapy and the war on cancer. Nat Rev Cancer. 2005;5:65-72.

DallaVechia L, Gnoatto SCB, Gosmann G. Derivados oleananos e ursanos e sua importância na descoberta de novos fármacos com atividade antitumoral, anti-inflamatória e antioxidante. Quím Nova. 2009;32(5):1245-1252.

Da Silva DL, Terra BS, Lage MR, Ruiz ALTG, Da Silva CC, De Carvalho JE, et al. Xanthenones: Calixarenes-catalyzed syntheses, anticancer activity and QSAR studies. Org \& Biomol Chem. 2015;13(11):3280-3287.

Dos Santos DS, Piovesan LA, D'oca CRM, Hack CRL, Treptow TGM, Rodrigues MO, et al. Antiproliferative activity of synthetic fatty acid amides from renewable resources. Bioorg \& Med Chem. 2015;23(2):340-347.

Ferlay J, Soerjomataram I, Ervik M, Forman D, Bray F, Dikshit R, et al. GLOBOCAN 2012: Estimated cancer incidence, mortality and prevalence worldwide in 2012. [cited 2016 July 08]. Available from: http://globocan.iarc.fr/Pages/fact_sheets_ cancer.aspx.

Fotie J, Bohle DS, Leimanis ML, Georges E, Rukunga G, Nkengfack AE. Lupeol long-chain fatty acid esters with antimalarial activity from Holarrhena floribunda. J Nat Prod. 2006;69(1):62-67. 
Gali-Muhtasib H, Hmadi R, Kareh M, Tohme R, Darwiche N. Cell death mechanisms of plant-derived anticancer drugs: beyond apoptosis. Apoptosis. 2015;20(12):1531-1562.

Gallo MBC, Sarachine MJ. Biological activities of lupeol. Int J Biomed Pharmaceut Sci. 2009;3:46-66.

Galmarini D, Galmarini CM, Galmarini FC. Cancer chemotherapy: a critical analysis of its 60 years of history. Crit Rev Oncol Hemat. 2012;84(2):181-199.

Geetha T, Varalakshmiu P, Latha RM. Effect of triterpenes from Crataeva nurvala stem bark on lipid peroxidation in adjuvant induced arthritis in rats. Pharmacol Res. 1998;37(3):191-195.

Gurovic MS, Castro MV, Richmond VJ, Faraoni MB, Maier MS, Murray AP. Tritepenoids with acethylcholinesterase inhibition from Chuquiraga erinacea D. Don. Supbsp. Erinacea (Asteraceae). Planta Med. 2010;76(6):607-610.

Harada H, Yamashita U, Kurihara H, Fukushi E, Kawabata J, Kamei Y. Antitumor activity of palmitic acid found as a selective cytotoxic substance in a marine red alga. Anticancer Res. 2002;22(5):2587-2590.

Lachance H, Wetzel S, Kumar K, Waldmann H. Charting, navigating, and populating natural product chemical space for drug discovery. J Med Chem. 2012;55(13):5989-6001.

Laszczyk MN. Pentacyclic triterpenes of the lupane, oleanane and ursane group as tools in cancer therapy. Planta Med. 2009;75(15):1549-1560.

Li W, Hao J, Xiao Y. Synthesis and in vitro antitumor activities of lupeol dicarboxylic acid monoester derivatives. Arch Pharmacol Res. 2013;36(12):1447-1453.

Magalhães CG, Ferrari FC, Guimarães DAS, Silva GDF, Duarte LP, Figueiredo RC, et al. Maytenus salicifolia: triterpenes isolated from stems and antioxidant property of extracts from aerial parts. Braz J Pharmacogn. 2011;21(3):415-419.

Mahato SB, Kundu AP. ${ }^{13} \mathrm{C}$ NMR Spectra of pentacyclic triterpenoids - a compilation and some salient features. Phytochemistry. 1994;37(6):1517-1575.

Monks A, Scudeiro D, Skehan P, Shoemaker S, Paull K, Vistica D, et al. Feasibility of a high-flux anticancer drug screen using a diverse panel of cultured human tumor cell lines. J Nat Can Inst. 1991;83(11):757-766.
Newman DJ, Cragg GM. Natural products as sources of new drugs from 1981 to 2014. J Nat Prod. 2016;79(3):629-661.

Núñez MJ, Reyes CP, Jiménez IA, Moujir L, Bazzocchi IL. Lupane triterpenoids from Maytenus species. J Nat Prod. 2005;68(7):1018-1021.

Oishi-Tomiyasu R. Rapid Bravais-lattice determination algorithm for lattice parameters containing large observation errors. Acta Cryst A. 2012;68(Pt 5):525-535.

Reddy KP, Singh AB, Puri A, Srivastava AK, Narender T. Synthesis of novel triterpenoid (lupeol) derivatives and their in vivo antihyperglycemic and antidyslipidemic activity. Bioorg Med Chem Lett. 2009;19(15):4463-4466.

Saleem M, Maddodi N, Zaid MA, Khan N, Hafeez B, Asim M, et al. Lupeol inhibits growth of highly aggressive human metastatic melanoma cells in vitro and in vivo by inducing apoptosis. Clin Cancer Res. 2008;14(7):2119-2127.

Saleem M. Lupeol, a novel anti-inflammatory and anti-cancer dietary triterpene. Cancer Lett. 2009;285(2):109-115.

Salminen A, Lehtonen M, Suuronen T, Kaarniranta K, Huuskonen J. Terpenoids: natural inhibitors of NF-kB signaling with anti-inflammatory and anticancer potential. Cell Mol Life Sci. 2008;65(19):2979-2999.

Shahlaei M, Ghanadian SM, Ayatollahi AM, Mesaik MA, Abdalla OM, Afsharypour S, et al. Molecular modeling, structure activity relationship and immunomodulatory properties of some lupeol derivatives. Med Chem Res. 2013;22:1795-1803.

Siddique HR, Saleem M. Beneficial health effects of lupeol triterpene: a review of preclinical studies. Life Sci. 2011;88(78):285-293.

Sudhahar V, Kumar SA, Varalakshmi P. Role of lupeol and lupeol linoleate on lipemic-oxidative stress in experimental hypercholesterolemia. Life Sci. 2006a;78(12):1329-1335.

Sudhahar V, Kumar SA, Varalakshmi P. Effect of lupeol and lupeol linoleate on lipemic - hepatocellular aberrations in rats fed a high cholesterol diet. Mol Nutr Food Res. 2006b;50(12):12121219.

Sudhahar V, Kumar SA, Sudharsan PT, Varalakshmi P. Protective effect of lupeol and its ester on cardiac abnormalities in experimental hypercholesterolemia. Vasc Pharmacol. 2007a;46(6):412-418. 
Sudhahar V, Kumar SA, Mythili Y, Varalakshmi P. Remedial effect of lupeol and its ester derivative on hypercholesterolemiainduced oxidative and inflammatory stresses. Nut Res 2007b;27(12):778-787.

Sudhahar V, Kumar SA, Varalakshmi P, Sujatha V. Protective effect of lupeol and lupeol linoleate in hypercholesterolemia associated renal damage. Mol Cell Biochem 2008;317(1-2):1120.

Sudhahar V, Veena CK, Varalakshmi P. Antiurolithic effect of lupeol and lupeol linoleate in experimental hyperoxaluria. J Nat Prod 2008;71(9):1509-1512.
Sunitha S, Nagaraj M, Varalakshmi P. Hepatoprotective effect of lupeol and lupeol linoleate on tissue antioxidant defense system in cadmium-induced hepatotoxicity in rats. Fitoterapia. 2001;72(5):516-523.

Sultana NJ. Clinically useful anticancer, antitumor, and antiwrinkle agent, ursolic acid and related derivatives as medicinally important natural product. Enz Inhibit Med Chem. 2011;26(5):616-642.

Wagner H, Bladt S. Plant drug analysis: a thin layer chromatography atlas. Berlin: Springer; 1996. 384 p.

Received for publication on $08^{\text {th }}$ February 2017 Accepted for publication on $01^{\text {st }}$ June 2017 